Check for updates

Cite this: RSC Adv., 2017, 7, 25175

Received 24th January 2017 Accepted 26th April 2017

DOI: 10.1039/c7ra01085k

rsc.li/rsc-advances

\section{Cinobufagin, a bufadienolide, activates ROS- mediated pathways to trigger human lung cancer cell apoptosis in vivo $\dagger$}

\author{
Panli Peng, (iD ab Junhong Lv, ${ }^{c}$ Changqing Cai, ${ }^{b}$ Shaohuan Lin, ${ }^{c}$ Enqing Zhuo ${ }^{\mathrm{b}}$ \\ and Senming Wang*a
}

Lung cancer, as the most common malignancy worldwide, is one of the most threatening diseases for human beings. Chan Su, an ethanolic extract from skin and parotid venom glands of the Bufo bufo gargarizans Cantor, is widely used as a traditional Chinese medicine in cancer therapy. Bufadienolides are cardiotonic steroids isolated from the skin and parotid venom glands of toad Bufo bufo gargarizans Cantor with excellent anticancer activity. Unfortunately, little information about the in vivo effects and action mechanisms of bufadienolides on human lung cancer cells is available. Therefore, in this study, the anticancer activities of Cinobufagin $(\mathrm{CnBu})$, bufalin $(\mathrm{Bu})$ and arenobufagin $(\mathrm{ArBu})$ were evaluated in vivo and in vitro and the underlying mechanisms were elucidated. The results showed that $\mathrm{CnBu}$ exhibited higher anticancer efficacy than Bu and AuBu against a panel of five lung cancer cells (A549, $\mathrm{NCl}-\mathrm{H} 460, \mathrm{H} 1299$, Sk-mes-1 and Calu-3) with $\mathrm{IC}_{50}$ values ranging from 2.3-6.7 $\mu \mathrm{M}$. Moreover, $\mathrm{CnBu}$ showed much higher selectivity between cancer and normal cells, as suggested by its $I C_{50}$ value towards BEAS-2B human normal bronchial epithelial cells reaching $22.3 \mu \mathrm{M}$. CnBu also significantly inhibited the growth of A549 cells in a dose-dependent manner through anti-migration and anti-invasion. Moreover, $\mathrm{CnBu}$ effectively induced apoptosis in A549 cells by triggering caspase activation through intrinsic and extrinsic pathways. Treatment of $\mathrm{CnBu}$ also significantly caused mitochondrial fragmentation and ROS overproduction in cancer cells. Interestingly, the treatment of ROS scavengers significantly inhibited apoptosis caused by $\mathrm{CnBu}$ in $\mathrm{A} 549$ cells, further demonstrating the important role of ROS on $\mathrm{CnBu}$ caused cell apoptosis. Moreover, $\mathrm{CnBu}$ also exhibited strong in vivo antitumor efficacy by inhibiting the tumor growth through induction of apoptosis in vivo and activation of p53 phosphorylation. In summary, our findings demonstrate the anticancer ability of bufadienolides in vivo against human lung cancer.

\section{Introduction}

Lung cancer, as one of the most frequently occurring cancers throughout the world, has plagued human beings for a fairly long time. According to epidemiological studies, about $80 \%$ of lung cancers are non-small cell lung cancer (NSCLC), which would lead to poor prognosis, and the rest (at about 20\%) is small cell lung cancer. ${ }^{1}$ Till now, the clinical treatment regimes for lung cancer include surgery, chemotherapy and radiotherapy. While chemotherapy has significantly improved the therapeutic effect and the quality of patients' lives, its

\footnotetext{
${ }^{a}$ Department of Oncology, Zhujiang Hospital, Southern Medical University, Guangzhou, Guangdong 510282, China. E-mail: senmingwang137@yeah.net

${ }^{b}$ Oncology No. 2 Department, Guangdong Second Provincial General Hospital, Guangzhou 510317, China

'Thoracic Surgeons Department, Guangdong Second Provincial General Hospital, Guangzhou 510317, China
}

$\dagger$ Electronic supplementary information (ESI) available. See DOI: $10.1039 / \mathrm{c} 7 \mathrm{ra} 01085 \mathrm{k}$ anticancer efficacy and safety remain critical barriers for cancer treatment. For instance, multidrug resistance is the major cause for the failure of chemotherapy. ${ }^{2}$ Therefore, there is still an urgent need to discover novel agents with therapeutic potentials for lung cancer treatment. ${ }^{3}$ The recent interest of scientists has been focused on seeking natural products as chemotherapeutic agents for lung cancer treatment. ${ }^{4-9}$ For instance, studies have reported hyperoside induced lung cancer cell apoptosis and suppressed inflammatory response via caspase-3- and NF- $\kappa \mathrm{B}-$ mediated signaling pathway. ${ }^{6}$ Meng and co-workers found out that luteolin exhibited a pro-apoptotic effect and anti-migration effects on lung adenocarcinoma cells by regulation of the MEK/ ERK-mediated pathway. ${ }^{7}$ These studies have confirmed the application potential of natural products in therapy of lung cancers.

Toad venom (Venenum Bufonis, also called Chan'su), extracted from the dried skin secretions of giant toads (Bufo gargarizans Cantor), has now been widely used as a traditional Chinese medicine for the therapy of various kinds of cancers. ${ }^{10-14}$ In traditional Chinese medicine, amphibian skin 
extract has been used for the treatments of several diseases. ${ }^{\mathbf{1 5 , 1 6}}$ Many studies have reported that toad skin extract and its components enabled to inhibit cancer cell growth, migration and invasion via different mechanisms. ${ }^{10-12}$ Qi and Cheng et al. have reviewed that Cinobufacini and its major active compounds such as Bufalin, Cinobufagin, Resibufogenin and Telocinobufagin have potent anticancer properties, including inhibition of cell proliferation, induction of cell differentiation, induction of apoptosis, disruption of the cell cycle, inhibition of cancer angiogenesis, reversal of multi-drug resistance, and regulation of the immune response. ${ }^{17,18} \mathrm{Gao}$ et al. reviewed the abundance of natural bufadienolides such as crassulaceae (plant-sourced) and bufonidae (animal-sourced) and their products obtained by biotransformation. ${ }^{19}$ Recently, scientists and researchers focus on screening the anticancer ability of active components from the skin extracts of toad venom. Researches have demonstrated that the main active components in toad skins are hydrophilic indole alkaloids (such as bufotenidine and cinobufotenine) and lipophilic steroidal cardiac glycosides (such as bufadienolides).,20 Bufadienolidetype cardiotonic steroids have been identified as major active components and marker compounds of Venenum Bufonis. ${ }^{21}$ Nowadays, bufadienolides including bufotalin, bufalin and resibufogenin etc. have been found to show potent cytotoxic and growth-inhibitory activity against various human cancer cells including lung cancer cells., ${ }^{5,22-30}$ For instance, Lee et al. have demonstrated the cyto-/genotoxic effects of ethanolic extract from Chan $\mathrm{Su}$ on human lung carcinoma cells. ${ }^{31}$ SchmedaHirschmann et al. have found out that the new species of argininyl bufadienolide esters from the "cururú" toad Rhinella (Bufo) schneideri have novel antiproliferative activity. ${ }^{32}$ Liu and co-workers have reported that the novel bufalin derivative exhibited higher apoptotic effect against lung cancer cells and lower acute toxicity in mice model. ${ }^{33}$ Chen's group has reported that bufadienolides exhibited the strongest cytotoxic effect against lung carcinoma cell line, including SPC-A-1 cells and A549 cells. $^{15}$ Taken together, these results have supported the therapeutic potential of toad venom and its active components in treatments of lung cancers.

Cinobufagin $(\mathrm{CnBu})$ is a novel bioactive component from the traditional Chinese medicine Asiatic toad Bufo bufo gargarizans, and has been reported to exhibit potent pharmacological activity. ${ }^{34-39}$ In particular, recent studies have demonstrated the broad-spectrum cytotoxicities of $\mathrm{CnBu}$ against various human cancer cell lines. ${ }^{34,35,37,39}$ For instance, Zhang et al. have shown that $\mathrm{CnBu}$ effectively inhibited cancer growth by triggering AKTmediated intrinsic apoptotic pathway in non-small lung cancer cells. ${ }^{39} \mathrm{Ma}$ et al. found out that $\mathrm{CnBu}$ could induce autophagymediated cell death in human osteosarcoma U2OS cells through the ROS/JNK/p38-mediated signaling pathway. ${ }^{37}$ Chen et al. showed that $\mathrm{CnBu}$ could be used to treat paw cancer pain by modulating the expression of local $\beta$-endorphin. ${ }^{35}$ These results have demonstrated the potential of $\mathrm{CnBu}$ in cancer therapy. However, the in vivo anticancer effects of $\mathrm{CnBu}$ on human lung cancer cells and the underlying action mechanisms were still unknown. Therefore, in this study, the in vitro and in vivo anticancer activities of $\mathrm{CnBu}$ were examined against human lung cancer cells, and the underlying action mechanisms were also investigated. Our findings indicated that $\mathrm{CnBu}$ effectively inhibited the growth, migration and invasion of lung cancer cells via the induction of cell apoptosis. Treatment of cancer cells also significantly activated mitochondrial fragmentation and ROS overproduction. Interestingly, addition of ROS scavenger significantly inhibited the $\mathrm{CnBu}$-induced cell death, indicating the important role of ROS on triggering cell apoptosis. Moreover, $\mathrm{CnBu}$ exhibited strong anti-proliferative efficacy in vivo through the induction of apoptosis in vivo and activation of p53 phosphorylation.

\section{Results and discussion}

\section{Inhibition of lung cancer cell proliferation, migration, and invasion induced by $\mathrm{CnBu}, \mathrm{Bu}$ and $\mathrm{ArBu}$}

The purity of $\mathrm{CnBu}$ was demonstrated by using high performance liquid chromatography (HPLC) before screening its cytotoxicity (Fig. S1 and $\mathrm{S} 2 \dagger$ ). The anticancer activities of $\mathrm{CnBu}$, $\mathrm{ArBu}$ and $\mathrm{Bu}$ (Fig. 1A) on five human lung cancer cell lines (A549, NCI-H460, H1299, Sk-mes-1 and Calu-3) and BEAS-2B human normal bronchial epithelial cells were first evaluated. After $72 \mathrm{~h}$ incubation, the cell viability treated with $\mathrm{CnBu}, \mathrm{ArBu}$ and $\mathrm{Bu}$ was determined by MTT assay. As shown in Fig. 1B, $\mathrm{CnBu}$ exhibited stronger anticancer ability against five lung cancer cells (A549, NCI-H460, H1299, Sk-mes-1 and Calu-3) than that of $\mathrm{ArBu}$ and $\mathrm{Bu}$, with the $\mathrm{IC}_{50}$ values ranging from 2.3-6.7 $\mu \mathrm{M}$. Importantly, CnBu showed much higher selectivity between cancer and normal cells than that of $\mathrm{ArBu}$ and Bu treatment, as evidenced by the higher $\mathrm{IC}_{50}$ value towards BEAS-2B human
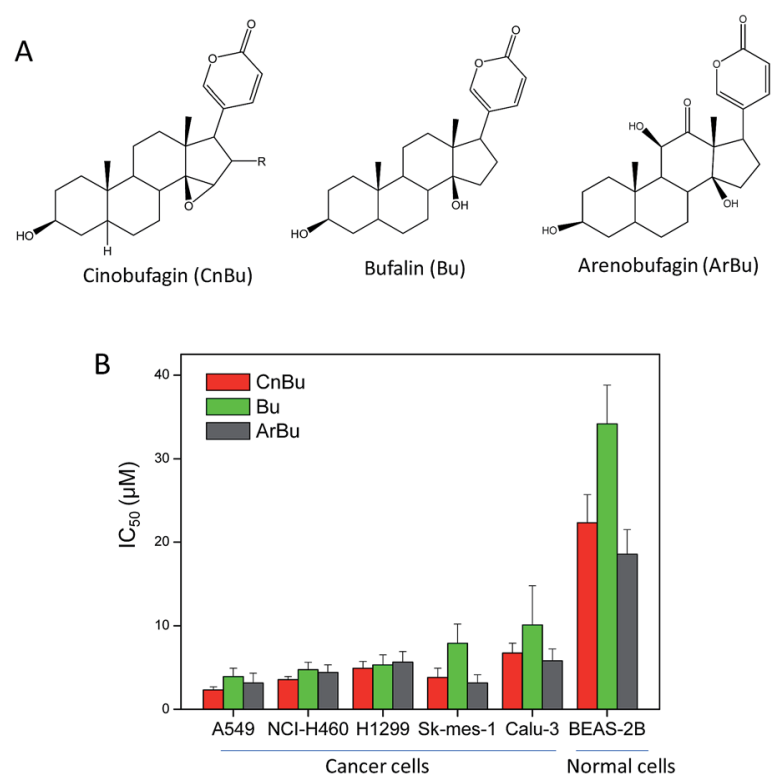

Fig. 1 In vitro anticancer activities of Cinobufagin ( $\mathrm{CnBu}$ ), bufalin (Bu) and arenobufagin ( $\mathrm{ArBu}$ ). (A) Chemical structure of $\mathrm{CnBu}, \mathrm{Bu}$ and $\mathrm{ArBu}$. (B) Cytotoxicity of $\mathrm{Bu}$ and $\mathrm{ArBu}$ towards human cancer and normal cells. Human lung cancer cells and normal cells were treated with different concentrations of $\mathrm{CnBu}, \mathrm{Bu}$ and $\mathrm{ArBu}$ for $72 \mathrm{~h}$, and the cell viability was examined by MTT assay. 


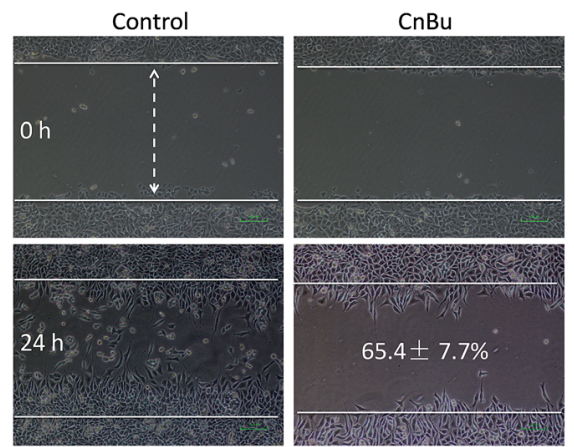

Fig. 2 Effects of CnBu on A549 cell migration. The A549 cells were treated with different concentrations of $\mathrm{CnBu}$ for $24 \mathrm{~h}$ and photographed using a phase-contrast microscope (200×, Nikon TS100).

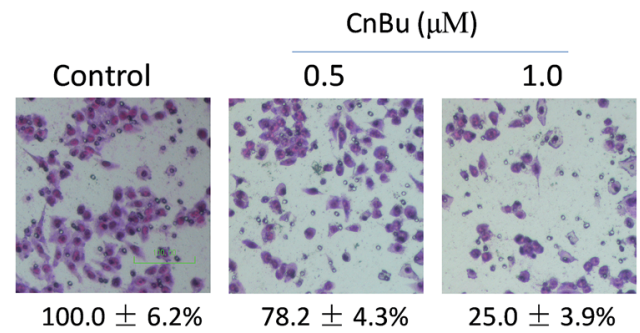

Fig. 3 Effects of CnBu on A549 cell invasion. Cells were exposed to different $\mathrm{CnBu}$ concentrations for $24 \mathrm{~h}$ and photographed using a phase-contrast microscope (200x, Nikon TS100).

normal bronchial epithelial cells (reaching to $22.3 \mu \mathrm{M}$ ). Among the different types of lung cancer cells, A549 cells were the most vulnerable cell line towards $\mathrm{CnBu}$ treatment, thus A549 cells were selected as the cell model for further mechanism studies. Because lung cancer cells were highly metastatic, we next examined the anti-metastatic effect of $\mathrm{CnBu}$ on A549 cells in vitro. In this study, wound closure assay and transwell migration assay were performed to evaluate the invasion and migration ability of A549 cells after the treatment of $\mathrm{CnBu}$. Before the experiment, we have confirmed that $\mathrm{CnBu}$ at 2 and $4 \mu \mathrm{M}$ showed no growth inhibitory effect on A549 cells with the cell density at $1 \times 10^{6}$ per well. Under these experimental conditions, we found out that 2 and $4 \mu \mathrm{M}$ of $\mathrm{CnBu}$ effectively inhibited migration (Fig. 2) and invasion of A549 cells (Fig. 3). Above all, these results commonly suggest that $\mathrm{CnBu}$ exhibited strong inhibitory effect on cancer growth, invasion and migration.

\section{A549 cell apoptosis induced by $\mathrm{CnBu}$}

Cell apoptosis has been detected in various kinds of human chronic diseases especially in cancers. ${ }^{40}$ Therefore, apoptosis induced by drugs in cancer cells has been regarded as an efficient strategy to treat cancers. ${ }^{\mathbf{4 1}}$ Many studies have demonstrated that most anticancer drugs exhibited strong anticancer activities by triggering cell apoptosis. ${ }^{42}$ Based on our previous results, $\mathrm{CnBu}$ exhibited stronger anticancer ability than $\mathrm{ArBu}$ and $\mathrm{Bu}$. Hence, the mechanism of $\mathrm{CnBu}$-caused cell death was clarified and demonstrated by using TUNEL \& DAPI co-staining

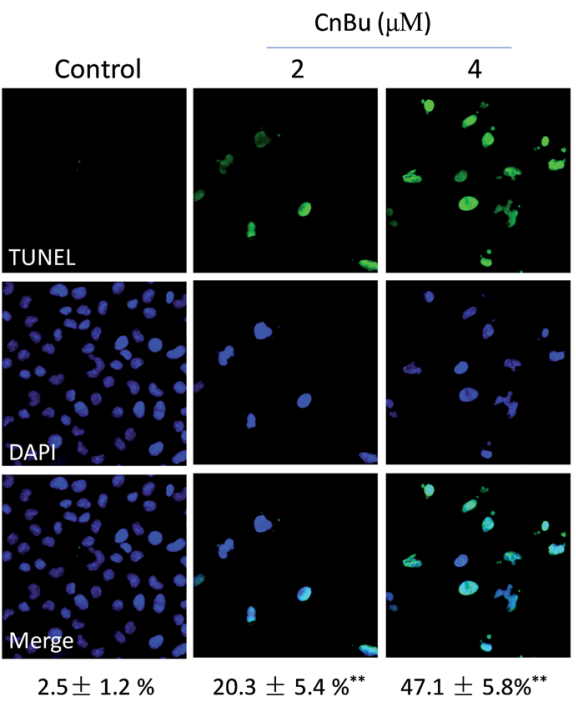

Fig. 4 Representative apoptotic DNA fragmentation and nuclear condensation induced by $\mathrm{CnBu}(24 \mathrm{~h})$ as determined via a TUNELDAPI co-staining assay (magnification, 200x).

assay. The fragmented DNA in the apoptotic cells can be detected and visualized by the fluorescence of FITC. The nucleus can be stained by DAPI. As shown in Fig. 4, DNA fragmentation and nuclear condensation were detected in A549 cells after treated with $\mathrm{CnBu}$, as evidenced by strong green fluorescence in a dose-dependent manner, which suggested that A549 cells were undergoing apoptosis after the exposure to $\mathrm{CnBu}$.

Caspases, playing an critical role on the induction of cell apoptosis, is a family of cysteine proteases that manipulate the enzymolysis process of series of substrates. ${ }^{\mathbf{4 3}}$ Activated caspases subsequently induced proteolytic cleavage of PARP and lead to cell apoptosis in the end. ${ }^{43}$ Cell apoptosis is mainly triggered by two mechanisms, including extrinsic (death receptor-mediated) and intrinsic (mitochondrial-mediated) apoptotic pathways. Therefore, the caspase activities including caspase-3, caspase-8 and caspase- 9 in cells treated with $\mathrm{CnBu}$ were evaluated to confirm the vital role of caspase in the process of cell apoptosis. As shown in Fig. 5, A549 cells treated with different concentrations of $\mathrm{CnBu}$

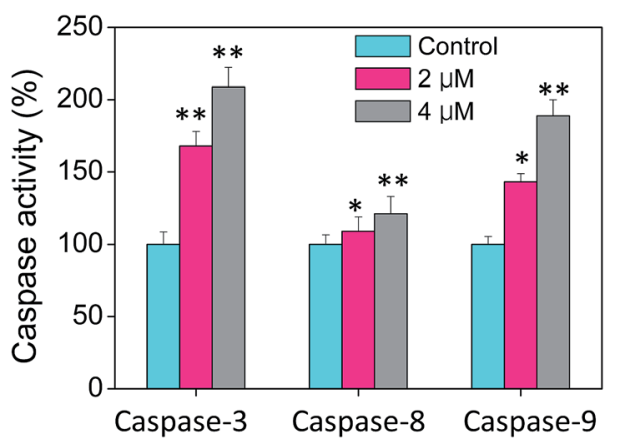

Fig. 5 Activation of caspases in A549 lung cancer cells by $\mathrm{CnBu}(24 \mathrm{~h})$ as examined by specific fluorogenic substrates. $* P<0.05$ and $* * P<$ 0.01 compared with the control. 
remarkably induced the activation of all three caspases in a dosedependent manner by quantifying fluorescence intensity. These results revealed that $\mathrm{CnBu}$ induced apoptosis in lung cancer cells through the activation of caspase.

\section{CnBu triggers mitochondria dysfunction and ROS overproduction}

Mitochondria dysfunction, as an important incidence in the process of apoptosis, have a vital role in triggering various apoptotic signals. ${ }^{34}$ Mitochondrial dysfunction mainly include mitochondrial fragmentation, decrease of mitochondrial membrane potential $\left(\Delta \psi_{\mathrm{m}}\right)$ which may lead to the release of factors contributing to the activation of apoptotic cell death. ${ }^{4 \mathbf{4}}$ As shown in Fig. 5, the much higher level of caspase-9 suggested that mitochondria play a much more important part in the process of cell apoptosis than that of the death receptormediated pathway. Correspondingly, in this study, the mitochondria fragmentation was observed in A549 cells after treated with $\mathrm{CnBu}$, as denoted by the white arrow, suggesting that $\mathrm{CnBu}$ induced apoptosis in lung cancer cell via initiation of mitochondria-mediated apoptotic pathways.

Reactive oxygen species (ROS) was found to play an critical role in cell apoptosis via activation of mitochondrial dysfunction. ${ }^{45}$ Overproduction of intracellular ROS may cause DNA damage and then initiate different apoptosis-related signaling pathways, such as p53 pathway. ${ }^{\mathbf{4 6 - 4 9}}$ Considerable evidence revealed that ROS have a significant influence on the initiation of signaling pathways in general chemotherapies. ${ }^{\mathbf{1 , 2 1 , 3 1 , 3 5 , 5 0 - 5 4}}$ Considering the observed mitochondria dysfunction in A549

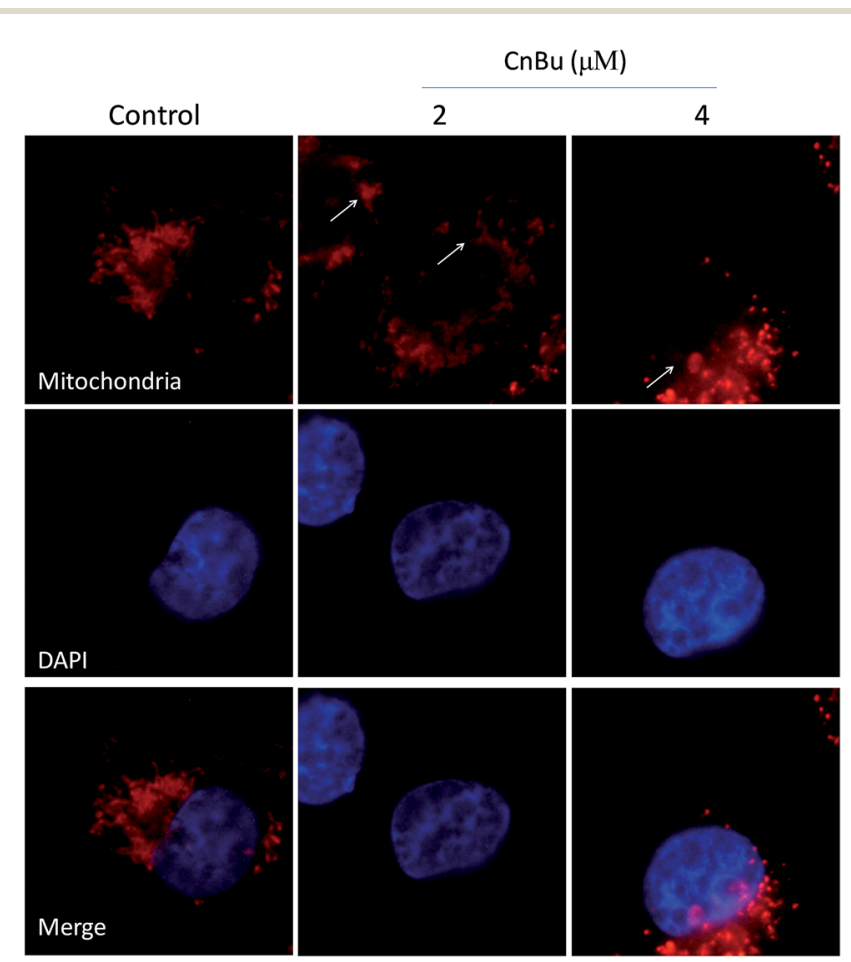

Fig. 6 Induction of mitochondrial fragmentation by $\mathrm{CnBu}$ (24 h). A549 cells mitochondria and nucleuses were visualized by red (MitoTracker Red CMXRos) and blue (DAPI) fluorescence, respectively.
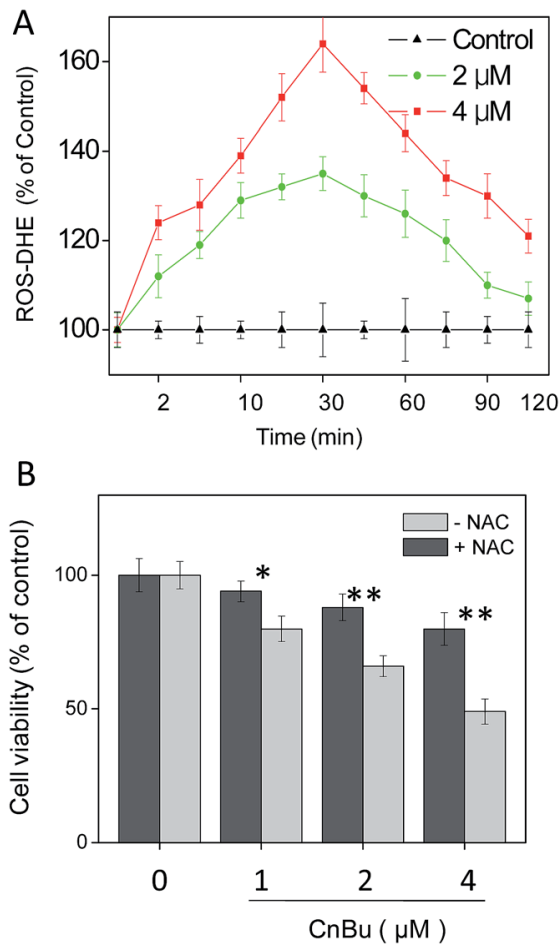

Fig. 7 Activation of ROS overproduction in A549 cells by $\mathrm{CnBu}$. (A) Time- and dose-dependent effects of $\mathrm{CnBu}$ on intracellular ROS generation in A549 cells. (B) Protective effects of antioxidant NAC on $\mathrm{CnBu}$-induced cell growth inhibition. The cells were pretreated with NAC (1 mM) for $2 \mathrm{~h}$ followed by co-incubation with different concentrations of Ru2. ${ }^{*} P<0.05$ and $* * P<0.01$ indicate significant difference between $-\mathrm{NAC}$ and $+\mathrm{NAC}$ groups.

cell after treatment of $\mathrm{CnBu}$ (Fig. 6), we next set out to evaluate the generation of ROS in A549 cells with DHE as the fluorescence probe. As shown in Fig. 7A, treatment of A549 cells with different concentrations of $\mathrm{CnBu}$ significantly induced the overproduction of ROS in a time- and dose-dependent manner. Moreover, to verify the importance of ROS in the process of cell apoptosis, $N$-acetylcysteine (NAC), a ROS scavenger, was introduced to evaluate its effects on the process of $\mathrm{CnBu}$-caused cell death. As shown in Fig. 7B, pre-incubation of the cells with NAC $(1 \mathrm{mM})$ for $2 \mathrm{~h}$ greatly suppressed $\mathrm{CnBu}$-induced cell death, which confirmed that ROS have an unparalleled influence on the apoptosis of human lung cancer cells induced by $\mathrm{CnBu}$.

\section{In vivo anticancer efficacy of $\mathrm{CnBu}$ through activation of p53 phosphorylation}

The antitumor efficacy of $\mathrm{CnBu}$ in vivo was evaluated in A549 xenograft nude mice. After treatment of i.p. (2.5 and $5.0 \mathrm{mg} \mathrm{kg}^{-1}$ body weight every other day) for four weeks (28 days), the tumor weight was remarkably reduced from $2.5 \mathrm{~g}$ to 1.6 and $1.1 \mathrm{~g}$ respectively. The tumor-inhibition rate reached to $36 \%$ and $56 \%$ respectively (Fig. $8 \mathrm{~A}$ ). The tumor volume was dramatically decreased to $68 \%$ and $46 \%$ of control group (Fig. $8 \mathrm{~B}$ and C). Furthermore, the body weight of the mice with drug treatment maintained constant in the whole treatment process. Taken 


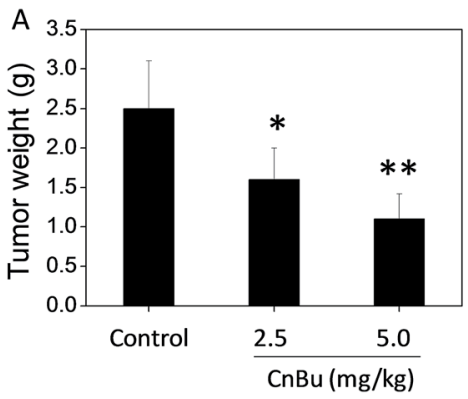

C

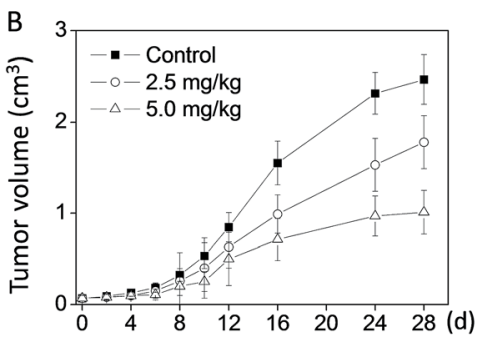

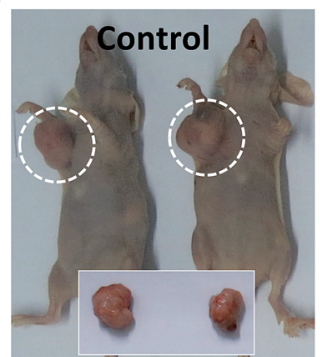

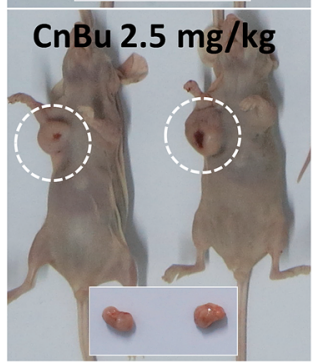

Fig. 8 In vivo antitumor efficacy and action mechanisms of $\mathrm{CnBu}$. Inhibitory effects of $\mathrm{CnBu}$ on $\mathrm{A} 549$ xenograft tumor weight (A) and volume (B) ( 2.5 or $5.0 \mathrm{mg} \mathrm{kg}^{-1}$ ) for 28 days. *, **, $P<0.01$ versus the control. (C) Changes of tumor volume in A549 xenograft nude mice between control group and treatment group $\left(2.5 \mathrm{mg} \mathrm{kg}^{-1}\right.$ of $\mathrm{CnBu}$ ) for 28 days.

together, these results verify the strong in vivo antitumor activity and safety of $\mathrm{CnBu}$ in A549 xenograft nude mice.

Histological and immunofluorescent analysis was introduced to study the mechanism involved in $\mathrm{CnBu}$-induced growth inhibition in vivo. As shown in Fig. 9, from the results of TUNAL-DAPI co-staining assay, significant increase of DNA fragmentation was observed as evidenced by the increase of the green fluorescence, indicating the occurrence of cell apoptosis in vivo. Moreover, as shown in Fig. 10, significant inhibition of

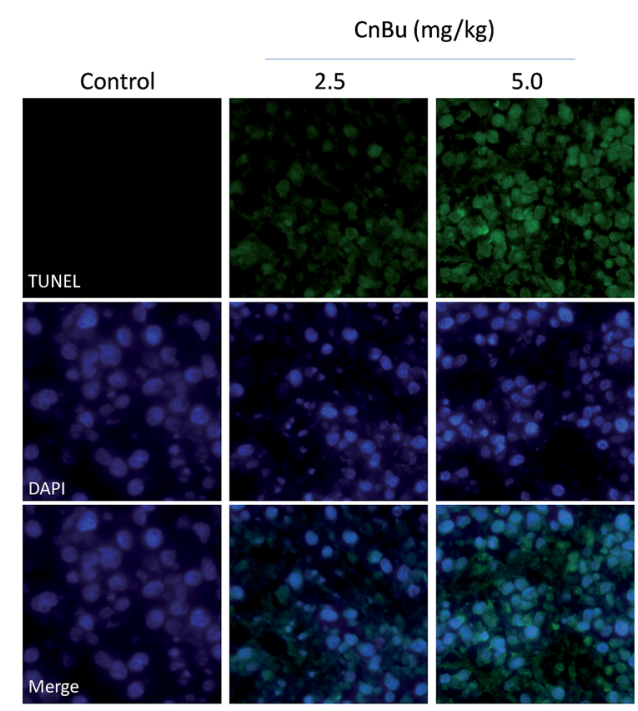

Fig. 9 Immunofluorescent analysis of TUNEL \& DAPI co-staining in tumor sections from $\mathrm{CnBu}$-treated xenograft nude mice. The mice were treated with $2.5 \mathrm{mg} \mathrm{kg}^{-1}$ or $5 \mathrm{~kg} \mathrm{mg}^{-1} \mathrm{CnBu}$ for 28 days.

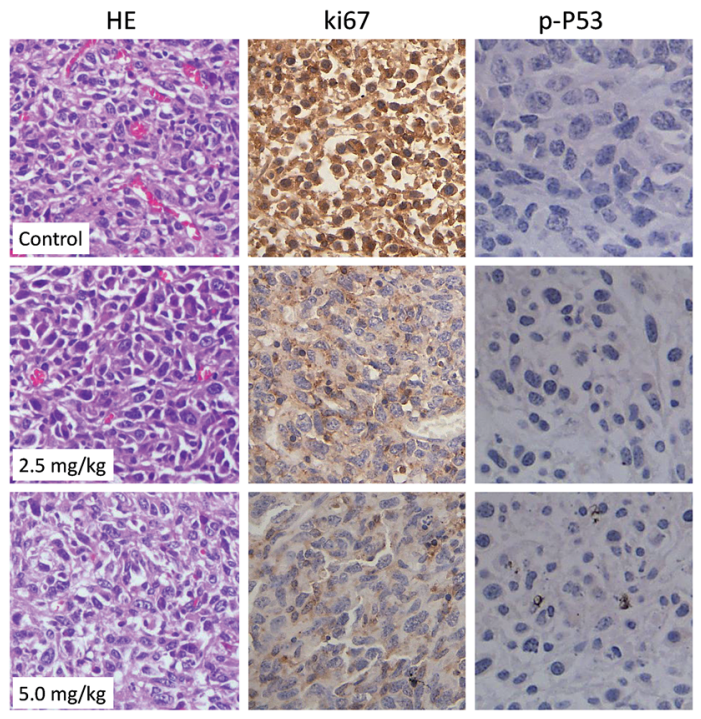

Fig. $10 \mathrm{HE}$ staining and immunohistochemical analysis of the expression levels of Ki-67 and phosphorylated p53 (p-P53) in A549 xenograft tumor treated with $\mathrm{CnBu}$ for 28 days.

blood vessel formation and cancer cell density was also observed in tumor after administered with 2.5 and $5.0 \mathrm{mg} \mathrm{kg} \mathrm{kg}^{-1}$ $\mathrm{CnBu}$. The expression of Ki-67, a biomarker of proliferation, was remarkably suppressed with treatment of different concentrations of $\mathrm{CnBu}$ in a dose-dependent manner. Furthermore, the expression of phosphorylated p53 (p-p53) increased significantly after 28 days of treatment with $\mathrm{CnBu}$.

Taken together, all these results demonstrated that $\mathrm{CnBu}$ significantly suppressed the proliferation of tumor by initiating cell apoptosis with the involvement of p53 phosphorylation.

\section{Conclusions}

In summary, the in vitro and in vivo anticancer activities of $\mathrm{CnBu}$ were examined against human lung cancer cells, and the underlying mechanisms were elucidated in this study. Our findings indicated that $\mathrm{CnBu}$ effectively inhibited lung cancer cell growth, migration, and invasion via the induction of cell apoptosis. Treatment of $\mathrm{CnBu}$ significantly led to the mitochondrial fragmentation and ROS overproduction in lung cancer cells. Interestingly, addition of ROS scavenger significantly inhibited the $\mathrm{CnBu}$-induced cell death, indicating the important roles of ROS in cell apoptosis. Moreover, $\mathrm{CnBu}$ exhibited strong antitumor activity in vivo by inhibiting tumor growth through induction of cell apoptosis in vivo and activation of p53 phosphorylation. Hence, this study confirms the anticancer efficacy of bufadienolides in the treatment of human lung cancers.

\section{Materials and methods}

\section{Reagents and materials}

Cinobufagin $(\mathrm{CnBu})$, arenobufagin $(\mathrm{ArBu})$ and bufalin $(\mathrm{Bu})$ standards were provided by Tauto Biotech Co., Ltd. (Shanghai, 
China). The purity of $\mathrm{CnBu}$ was verified by using high performance liquid chromatography (HPLC). Other reagents were purchased from Sigma-Aldrich (St Louis, MO, USA).

\section{Cell lines and cell culture}

Human lung cancer cell lines used in this study (A549, NCIH460, H1299, Sk-mes-1 and Calu-3) and BEAS-2B human normal bronchial epithelial cells were obtained from American Type Culture Collection (ATCC, Manassas, VA) and Guangzhou Jennio Biotech Co., Ltd (Guangzhou, China). The cells were cultured and maintained in RPMI 1640 and DMEM medium supplemented with fetal bovine serum (10\%), penicillin (100 units $\mathrm{ml}^{-1}$ ) and streptomycin (50 units $\mathrm{ml}^{-1}$ ) at $37{ }^{\circ} \mathrm{C}$ in a humid incubator with $5 \% \mathrm{CO}_{2}$.

\section{MTT assay}

The effects of the tested drugs on the cell growth were determined by MTT cell viability assay on a microplate spectrophotometer (VERSA max, Molecular Devices). ${ }^{55}$

\section{Cell migration and invasion}

To evaluate the inhibition effect of $\mathrm{CnBu}$ on cell migration and invasion, wound closure assay and transwell migration assay were performed as previously described. ${ }^{56}$

\section{TUNEL assay and DAPI staining}

TUNEL-DAPI co-staining assay kit (Roche) was employed to detect the apoptotic cell death induced by $\mathrm{ArBu}$ as previously described. ${ }^{57}$

\section{Determination of the caspase activity}

The activities of caspase-3, - 8 and -9 in cells treated with the tested drugs were monitored by fluorometric method using specific caspase substrates (Ac-DEVD-AFC for caspase-3, AcIETD-AFC for caspase-8 and Ac-LEHD-AFC for caspase-9).$^{\mathbf{5 8}}$

\section{Measurement of intracellular reactive oxygen species (ROS) generation}

The effects of CnBu on intracellular ROS generation in A549 cells were monitored by DHE assay. ${ }^{59}$ The ROS levels were expressed as percentage of treated cells to that of control.

\section{Tumor xenograft in nude mice}

A549 cells $\left(5 \times 10^{6}\right)$ suspended in $200 \mu \mathrm{l}$ PBS were injected s.c into the right lower hind flank of each six-week-old male nude mouse. The mice were randomly assigned into three groups with 5 mice in each group. After ten days, ArBu dissolved in the solution $\left(\mathrm{DMF}_{\mathrm{v}}\right.$ : Tween-80 ${ }_{\mathrm{v}}:$ saline $\left._{\mathrm{v}}=10: 2: 88\right)$ was given i.p. (2, $4 \mathrm{mg} \mathrm{kg}^{-1}$ body weight every other day) for 20 days. Body weights and tumor dimensions were monitored as previously described ${ }^{60}$ Animals were maintained in accordance with the guidelines of the Southern Medical University, China, and approved by the institutional ethical committee (IEC) of Southern Medical University.

\section{Histology and immunohistochemistry}

Glutaraldehyde-fixed tumor specimens were embedded with paraffin and cut into $5 \mu \mathrm{m}$ thin sections. Each tissue section was deparaffinized and underwent hematoxylin and eosin for histology observation. Immunohistochemistry analysis was performed with anti-p-p53 (Ser $\left.{ }^{15}\right)$ and ki67 antibody (1 : 100) and biotinylated IgG antibody. ${ }^{60}$ To identify the apoptosis in tumor section, TUNEL \& DAPI staining assay was performed according to the manufacturers' protocols.

\section{Statistical analysis}

In this study, all experiments were performed at least in triplicate, and the data were presented as mean \pm standard error. Difference between two groups was analyzed by two-tailed Student's test, and that among three or more groups was analyzed by one-way ANOVA multiple comparisons. Difference with $P<0.05(*)$ or $P<0.01(* *)$ was considered statistically significant.

\section{References and notes}

1 Y. Y. He, X. C. Zhang, J. J. Yang, F. Y. Niu, Z. Zeng, H. H. Yan, C. R. Xu, J. L. Guan, W. Z. Zhong, L. L. Yang, L. H. Guo and Y. L. Wu, Clin. Lung Cancer, 2014, 15, 441-447.

2 A. Rajeswaran, A. Trojan, B. Burnand and M. Giannelli, Lung Cancer, 2008, 59, 1-11.

3 P. S. Ong, L. Wang, D. M. Chia, J. Y. Seah, L. R. Kong, W. L. Thuya, A. Chinnathambi, J. A. Lau, A. L. Wong, W. P. Yong, D. Yang, P. C. Ho, G. Sethi and B. C. Goh, Cancer Lett., 2016, 381, 49-57.

4 K. Jiang, W. Wang, X. Jin, Z. Wang, Z. Ji and G. Meng, Oncol. Rep., 2015, 33, 2711-2718.

5 L. Lin, L. Ren, L. Wen, Y. Wang and J. Qi, Mol. Med. Rep., 2016, 14(3), 2832.

6 P. Lu, Biomed. Pharmacother., 2016, 82, 216-225.

7 G. Meng, K. Chai, X. Li, Y. Zhu and W. Huang, Chem.-Biol. Interact., 2016, 257, 26-34.

8 G. Meng, W. Wang, K. Chai, S. Yang, F. Li and K. Jiang, Internet J. Oncol., 2015, 46, 1007-1017.

9 J. Moore, M. Megaly, A. J. MacNeil, P. Klentrou and E. Tsiani, Biomed. Pharmacother., 2016, 83, 725-732.

10 Y. H. Dai, B. Shen, M. Y. Xia, A. D. Wang, Y. L. Chen, D. C. Liu and D. Wang, Molecules, 2016, 21, 1-5.

11 M. Nakata, S. Kawaguchi, A. Oikawa, A. Inamura, S. Nomoto, H. Miyai, T. Nonaka, S. Ichimi, Y. Fujita-Yamaguchi, C. Luo, B. Gao and W. Tang, Drug Discoveries Ther., 2015, 9, 417-421.

12 M. Nakata, S. Mori, Y. Kamoshida, S. Kawaguchi, Y. FujitaYamaguchi, B. Gao and W. Tang, BioSci. Trends, 2015, 9, 266-269.

13 C. X. Lu, K. J. Nan and Y. Lei, Anti-Cancer Drugs, 2008, 19, 931-939.

14 C. Oelkrug, M. Hartke and A. Schubert, Anticancer Res., 2015, 35, 635-643.

15 C. Liu, W. Cao, Y. Chen, D. Qu and J. Zhou, Pharmacogn. Mag., 2014, 10, 207-212. 
16 H. Huang, Y. Yang, C. Lv, W. Chang, C. Peng, S. Wang, G. Ge, L. Han, W. Zhang and R. Liu, J. Ethnopharmacol., 2015, 161, 175-185.

17 F. Qi, A. Li, Y. Inagaki, N. Kokudo, S. Tamura, M. Nakata and W. Tang, Int. Immunopharmacol., 2011, 11, 342-349.

18 Q. Li, T. Sun and K. Hu, China J. Tradit. Chin. Med. Pharm., 2010, 46(12), 2075-2078.

19 H. Gao, R. Popescu, B. Kopp and Z. Wang, Nat. Prod. Rep., 2011, 28, 953-969.

20 C. Liu, W. Cao, Y. Chen, D. Qu and J. Zhou, Pharmacogn. Mag., 2014, 10, 207-212.

21 H. Huang, Y. Yang, C. Lv, W. Chang, C. Peng, S. Wang, G. Ge, L. Han, W. Zhang and R. Liu, J. Ethnopharmacol., 2015, 161, 175-185.

22 Z. Wang, J. Wen, J. Zhang, M. Ye and D. Guo, Biomed. Chromatogr., 2004, 18, 318-322.

23 L. Wen, Y. Huang, X. Xie, W. Huang, J. Yin, W. Lin, Q. Jia and W. Zeng, Mediators Inflammation, 2014, 2014, 1-9.

24 X. F. Zhai, F. F. Fang, Q. Liu, Y. B. Meng, Y. Y. Guo and Z. Chen, BMC Complementary Altern. Med., 2013, 13, 1-6.

25 L. He, S. Ji, H. Lai and T. Chen, J. Mater. Chem. B, 2015, 3, 8383-8393.

26 X. Z. Yang, X. J. Du, Y. Liu, Y. H. Zhu, Y. Z. Liu, Y. P. Li and J. Wang, Adv. Mater., 2014, 26, 931-936.

27 M. Li, X. Yu, H. Guo, L. Sun, A. Wang, Q. Liu, X. Wang and J. Li, Tumor Biol., 2014, 35, 2461-2471.

28 D. M. Zhang, J. S. Liu, L. J. Deng, M. F. Chen, A. Yiu, H. H. Cao, H. Y. Tian, K. P. Fung, H. Kurihara, J. X. Pan and W. C. Ye, Carcinogenesis, 2013, 34, 1331-1342.

29 G. X. Xu and T. T. Wang, Int. J. Ophthalmol., 2010, 3, 128-131.

30 B. J. Li, H. Y. Tian, D. M. Zhang, Y. H. Lei, L. Wang, R. W. Jiang and W. C. Ye, Fitoterapia, 2015, 105, 7-15.

31 S. Lee, Y. Lee, Y. J. Choi, K. S. Han and H. W. Chung, J. Ethnopharmacol., 2014, 152, 372-376.

32 G. Schmeda-Hirschmann, C. Quispe, C. Theoduloz, P. T. de Sousa Jr and C. Parizotto, J. Ethnopharmacol., 2014, 155, 1076-1085.

33 M. Liu, L. X. Feng, P. Sun, W. Liu, W. Y. Wu, B. H. Jiang, M. Yang, L. H. Hu, D. A. Guo and X. Liu, PLoS One, 2016, 11, 1-18.

34 S. H. Baek, C. Kim, J. H. Lee, D. Nam, J. Lee, S. G. Lee, W. S. Chung, H. J. Jang, S. H. Kim and K. S. Ahn, Immunopharmacol. Immunotoxicol., 2015, 37, 265-273.

35 T. Chen, W. Hu, H. He, Z. Gong, J. Wang, X. Yu, T. Ai and L. Zhan, J. Evidence-Based Complementary Altern. Med., 2013, 2013, 1-9.

36 P. Li, Q. Song, T. Liu, Z. Wu, X. Chu, X. Zhang, Y. Zhang, Y. Gao, J. Zhang and L. Chu, Sci. World J., 2014, 2014, 1-10.

37 K. Ma, C. Zhang, M. Y. Huang, W. Y. Li and G. Q. Hu, Oncol. Rep., 2016, 36, 90-98.
38 Y. Yu, H. Wang, X. Meng, L. Hao, Y. Fu, L. Fang, D. Shen, $\mathrm{X}$. $\mathrm{Yu}$ and J. Li, J. Evidence-Based Complementary Altern. Med., 2015, 2015, 1-8.

39 G. Zhang, C. Wang, M. Sun, J. Li, B. Wang, C. Jin, P. Hua, G. Song, Y. Zhang, L. L. Nguyen, R. Cui, R. Liu, L. Wang and X. Zhang, Oncotarget, 2016, 7, 28935-28946.

40 K. Maiese, Z. Z. Chong, Y. C. Shang and S. Wang, Expert Opin. Ther. Targets, 2012, 16, 1203-1214.

41 T. Chen and Y. S. Wong, Cell. Mol. Life Sci., 2008, 65, 27632775.

42 T. Chen and Y. S. Wong, Int. J. Biochem. Cell Biol., 2009, 41, 666-676.

43 S. J. Riedl and Y. Shi, Nat. Rev., 2004, 5, 897-907.

44 T. Chen, W. Zheng, Y. S. Wong and F. Yang, Biomed. Pharmacother., 2008, 62, 77-84.

45 H. U. Simon, A. Haj-Yehia and F. Levi-Schaffer, Apoptosis, 2000, 5, 415-418.

46 I. R. Indran, M. P. Hande and S. Pervaiz, Cancer Res., 2011, 71, 266-276.

47 S. Park, Y. J. Son, K. W. Leong and H. S. Yoo, Nano Today, 2012, 7, 76-84.

48 L. Piconi, L. Quagliaro, R. Assaloni, R. Da Ros, A. Maier, G. Zuodar and A. Ceriello, Diabetes/Metab. Res. Rev., 2006, 22, 198-203.

49 C. H. Wong, K. B. Iskandar, S. K. Yadav, J. L. Hirpara, T. Loh and S. Pervaiz, PLoS One, 2010, 5, 1-12.

50 M. Arai, Y. Shibata, K. Pugdee, Y. Abiko and Y. Ogata, IUBMB Life, 2007, 59, 27-33.

51 J. K. Zhang, L. Yang, G. L. Meng, J. Fan, J. Z. Chen, Q. Z. He, S. Chen, J. Z. Fan, Z. J. Luo and J. Liu, Eur. J. Pharmacol., 2012, 689, 31-37.

52 Z. Luo, L. Yu, F. Yang, Z. Zhao, B. Yu, H. Lai, K. H. Wong, S. M. Ngai, W. Zheng and T. Chen, Metallomics, 2014, 6, 1480-1490.

53 T. Chen, Y. Liu, W. J. Zheng, J. Liu and Y. S. Wong, Inorg. Chem., 2010, 49, 6366-6368.

54 W. Cao, W. Zheng and T. Chen, Sci. Rep., 2015, 5, 1-11.

55 H. Luo, F. Wang, Y. Bai, T. Chen and W. Zheng, Colloids Surf., B, 2012, 94, 304-308.

56 Y. You, H. Hu, L. He and T. Chen, Chem.-Asian J., 2015, 10, 2744-2754.

57 W. Liu, X. L. Li, Y. S. Wong, W. J. Zheng, Y. B. Zhang, W. Q. Cao and T. F. Chen, ACS Nano, 2012, 6, 6578-6591.

58 X. L. Li, T. Chen, Y. S. Wong, G. Xu, R. R. Fan, H. L. Zhao and J. C. Chan, Int. J. Biochem. Cell Biol., 2011, 43, 525-534.

59 Y. Huang, L. He, W. Liu, C. Fan, W. Zheng, Y. S. Wong and T. Chen, Biomaterials, 2013, 34, 7106-7116.

60 Y. Huang, W. Huang, L. Chan, B. Zhou and T. Chen, Biomaterials, 2016, 103, 183-196. 